ISSUE BRIEF

\title{
Challenges to Higher Education's Most Essential Purposes
}

April 9, 2019

Kevin M. Guthrie

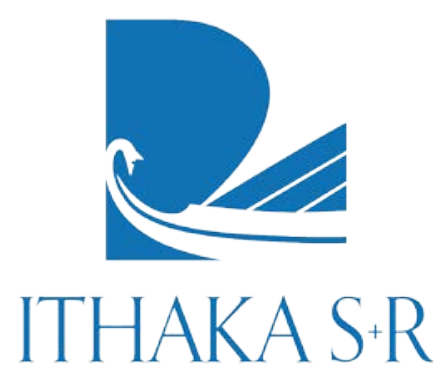




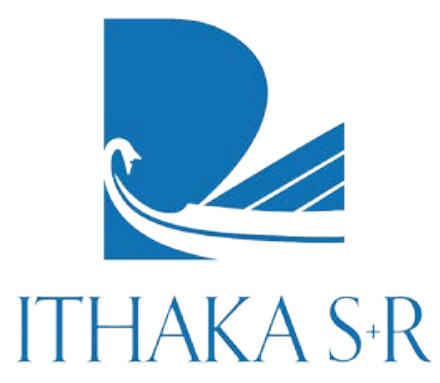

Ithaka $\mathrm{S}+\mathrm{R}$ provides research and strategic guidance to help the academic and cultural communities serve the public good and navigate economic, demographic, and technological change. Ithaka $\mathrm{S}+\mathrm{R}$ is part of ITHAKA, a not-for-profit organization that works to advance and preserve knowledge and to improve teaching and learning through the use of digital technologies. Artstor, J STOR, and Portico are also part of ITHAKA.
Copyright 2019 ITHAKA. This work is licensed under a Creative Commons Attribution-NonCommercial 4.0 International License. To view a copy of the license, please see http://creativecommons.org/licenses/by-nc/4.01.

ITHAKA is interested in disseminating this brief as widely as possible. Please contact us with any questions about using the report: research@ithaka.org. 
“[Higher education's most essential purposes] include educating students broadly so that they may lead productive lives in a civilized society; serving as engines of opportunity and social mobility; creating new knowledge of every kind, including work that either has no immediate market value or may even threaten some commercial end; encouraging and protecting the thoughtful critic and the dissenting voice; and defending cultural, moral, and intellectual values that no one can "price" very well."

William G. Bowen, Romanes Lecture, October 17, 2000

In his 2000 Romanes Lecture, entitled "At a Slight Angle to the Universe, the University in a Digitized, Commercialized Age," William Bowen anticipated many of the challenges higher education faces today. His incisive summary of the most important purposes of higher education offers a useful framework for assessing how higher education is fulfilling its uniquely important role supporting a vibrant democratic society. Those responsible for higher education's well-being, including presidents, administrators, trustees, faculty, and government policy makers, would do well to hold close these important values as they carry out their complementary roles leading the sector.

As we consider the challenges facing them in that endeavor, it is useful to remember that higher education is not a monolith. It is made up of many independent and diverse institutional types all operating to support and sustain internal organizational selfinterest even as they serve broader societal objectives. Higher education also serves a wide array of students with differing needs, resources and capacities. Problems and opportunities appear quite different from these various perspectives, and actions and interventions can yield different outcomes across different groups of institutions or across different types of students or faculty. Nevertheless, there are certain core principles that all of these institutions share, and there are certain aspects of their experience that are common.

One undeniable common factor is the changing information and media environment. Bowen anticipated this growing specter, and he highlighted it in his consideration of digitization and its impact on the sector. But even he likely did not foresee the impact and nature of the next generation of technological innovations lining up to dwarf the impacts of the past. This next powerful wave of change emanates from the trillions of sensors capturing data of every imaginable kind, the rapidly accelerating and exponential increases in computing power to process those data, and the potential for artificial intelligence and machine learning to operate in ways that fundamentally change many of the ways we work, learn, and interact; in short, the way we live our lives. 
The impact of this new wave of forces will be greater than the Industrial Revolution in the way it will transform our world. Paraphrasing from J oseph Aoun in his book about artificial intelligence: in the Industrial Revolution man learned to use machines as a substitute for physical labor, in this era we are learning to use machines as a substitute for intellectual labor. ${ }^{1} \mathrm{~J}$ ust as the shift to machines for physical labor transformed many aspects of society, so too will the continuing transition to the use of machines to support more fully our intellectual work.

The ultimate impact of the migration to artificial and machine-assisted intelligence is in many ways unforeseeable, but it is certain to be fundamental. The revolution to come will play out over decades, but because of the accelerating nature of technology and the rapid spread of information in today's world, we must begin now to prepare for its impact and indeed to help shape it to positive ends for society.

With this broad context, we outline a set of challenges and opportunities facing higher education, using the five purposes highlighted in Bowen's quote, along with reflections on the broader issues of financial, and in some cases perhaps even existential, threats to the future sustainability of colleges and universities.

\section{Educating Students to Lead Productive Lives}

The demand for and value of post-secondary education is greater than ever, and will continue to increase as machines take on more physical and basic intellectual tasks. The challenges to meeting those needs fall into a number of categories:

- Unsustainable cost of traditional methods of instruction. Methods of instruction that rely on small classes with an instructor are effective, but the effects of the notorious Baumol/ Bowen cost disease have made that methodology too expensive for all but the wealthiest institutions and is therefore not scale-able. How are colleges and universities going to find ways to "bend the cost curve" and increase the productivity of the education process?

- A changing population. Not only do higher education institutions need to be able to effectively educate more students of color, more students of modest financial means, and first-generation students in response to changing demographics, they also need to be able to educate students at different stages of their careers. This presents a variety of challenges at every stage of the education process, from admission through awarding a degree and on to meeting the needs of those who

1 Joseph E. Aoun, Robot Proof: Higher Education in the Age of Artificial Intelligence (Cambridge, MA: The MIT Press, 2017). 
have to return periodically for additional education throughout the course of a career.

- Educational technologies. Developments in technology point to the possibility of new forms of learning relying on machines as "tutors" that use data tracking student progress to recursively improve the quality of the knowledge and assistance provided to students. There is evidence that new teaching techniques facilitated by these technologies, such as flipped classrooms and engaged learning, offer promise, but demand that the roles of students and faculty in the learning process change in fundamental ways. Such change is very difficult to enable and support.

- Balancing the curriculum. Institutions need to respond to demand for new skills, such as computer programming or data science, even as they maintain and make the casefor important education in humanistic fields that are essential to dealing with ethical and values- based questions being raised by societal changes.

- Unbundling and rebundling. A number of information-based industries have been threatened and altered because new entrants provide a specialized service that disaggregates a bundled offering. There are many components to the higher education bundle, and of course what makes up the bundle varies by type and even individual institutions, but three broad categories might be worth considering as we contemplate future pressures on the sector: 1) education, and by that we specifically refer to the change in understanding and knowledge acquired over a period of time; 2) credentialing, and by that we mean the validation that a person has a particular skill or competence; and 3) selection, which refers to the process by which higher education institutions identify and assemble a group of talented people, an outcome that has proven to be very valuable to those who want to find talent, either for jobs or for further education. Higher education provides a talent matching role that makes the process of finding excellent people moreefficient.

- The Arms Race. There is an additional component that applies primarily to residential colleges, and drives up costs for institutions competing to attract students, and that is the need to provide a comfortable, safe, and sometimes almost luxurious environment for young men and women to transition to adulthood. Some refer to this as a student "arms race," as schools compete on quality of life related issues like beautiful technology-enabled dorms and campuses, great food, athletics facilities, etc. 


\section{Conducting Research and Creating New Knowledge}

The development of networked technologies has had a dramatic impact on scholarly communications and the research process. The first phase of that change- digitized information distributed via the network- has led to much wider dissemination of scholarly content around the world. The second phase of that evolution, enabled by the fact that the marginal cost of delivering content is nearly zero, has been downward pressure on the willingness to pay for content, leading to the emergence of the open access movement. There is increasing expectation that content should be delivered without charge to support its widest possible access and dissemination.

In response to these changes, larger scale publishers and aggregators of scholarly content have been shifting their business models to rely less on subscriptions to content and more on fees for services. They are moving "upstream" in the research process and assembling or building a variety of tools and services focused not only on the publication process, but also on helping scholars compile and manage data, collaborate with other researchers, and manage their work profiles. They are also building tools that help institutions evaluate, showcase and generate financial support for their faculty's work. Increasingly, the largest scientific publisher, Elsevier, offers a case in point. Elsevier is moving to offer an integrated set of services designed to deepen and broaden the level of engagement between and among Elsevier, scholars and academic institutions. Yet even as Elsevier makes progress executing this strategy, it is not clear that it can transition its business rapidly enough to maintain its profitability as the library market uses its leverage to withdraw from subscriptions, as new platforms and services emerge, and as the value proposition for research and publishing is transformed.

Publishers' strategies illustrate the opportunities to deliver new tools for supporting the research and publication process, but a more fundamental change to research may be associated with the growing importance of data analytics and machine learning. As highlighted in the introduction, entirely new areas and types of research are being created by the ability to capture, store, and analyze massive amounts of data. Computer science is being integrated into many traditional disciplines to create new interdisciplinary fields of research. Problems that were once intractable can now be pursued using raw computing power aimed at processing enormous amounts of data. Like access to great research libraries in the 20th century or access to the transcribed texts of the monks in the 6th century, access to massive amounts of data is essential to conducting cutting edge research in an increasing number of fields. Challenges facing colleges and universities as they are surrounded by “Big Data” include: 
- The largest datasets are not controlled by universities. Unfortunately, the largest datasets are often not available in the public domain or accessible by universities; they are held by corporations like Google, Facebook, and Amazon. It has been said that Google's effort to re-enter China is driven largely not by a desire for advertising revenue, but by a need to gain access to more data. With the insatiable need for data to feed the machine learning algorithms and to pursue answers to challenging problems in new ways, universities are finding themselves struggling to gain access to the raw materials for creating knowledge.

- Attracting top talent. Even the largest research universities are finding themselves at a disadvantage when trying to recruit top research talent. Professors are leaving the academy for jobs in industry, not only because of the potential to earn more money, but also to have access to the resources and data necessary to work on the most interesting intellectual problems.

- Potential to collaborate. Increasingly colleges and universities are positioning themselves to engage collaboratively not only with other universities, but also with private enterprise in order to get access to more data and compete to be at the cutting edge of research and discovery.

One consequence of these developments is that a smaller number of universities have the scale to compete in this domain, a trend that is increasing the gap between a small number of elite universities at the top, and all other colleges and universities far behind.

\section{Serving as Engines of Opportunity and Social Mobility}

If there is a risk of bifurcation in the research enterprise, it is perhaps even more pronounced on the education side of the college/ university mission. In the post-WWII era, in large measure due to the GI Bill and support for the returning military, higher education became an engine of opportunity that opened the door to the middle class for millions of Americans. Although the return on investment from a post- secondary degree has continued to be a great value, the cost of higher education, and the tuitions charged for earning a degree, have grown at a rate higher than that of all but the highest family incomes, making it increasingly difficult for people from middle- and lower-income backgrounds to afford a post-secondary education. A series of challenges have emerged to confront higher education as it attempts to maintain its place as a positive defender and facilitator of social and economic opportunity: 
- Undermatching. Many students choose not to go to the school that will challenge them more or that is beyond their local geographical region, a decision that often leads them to choose a school with lower levels of degree completion. And for colleges and universities, it is costly to reach students from all backgrounds and they don't always have an incentive to do so.

- Low levels of public support for institutions that serve the most students. Community colleges and regional public universities, which are the starting point for many of the most economically challenged students, are severely underfunded on a per-student basis, leading to low graduation rates and fewer resources for students trying to complete their educations.

- Changing demographics. Colleges and universities have to educate a more diverse set of students from a wider range of backgrounds.

- Increasing numbers of less-prepared students. More students coming out of high school aspire to attend college but unfortunately a larger share of them are not sufficiently prepared. More students are arriving at college needing more support to complete their educations and earn their degrees. Educating these students is costlier for colleges at a time when tuition needs to be held in check.

- Changing legal and policy environment. Approaches that support diversity and access to higher education for students of all backgrounds are losing government support and are being attacked in the courts.

- Students have lives. The majority of students have other commitments and face pressures outside their academic work; they are not in a position to make education their exclusive, or even a top priority. Colleges must continue to develop different ways to educate students who have to work or raise a family or meet other obligations while pursuing their education.

One dystopian potential outcome would be that, despite the best efforts of many institutions of all kinds, we could see a devolution back to a distinctly two-tiered system like what existed in 19th Century Britain. In this negative projection one can envision a very small number of well-endowed institutions that cater to the wealthy, well-prepared class as well as a small number of carefully picked representatives from various groups. These students would receive a world-class education, while most students would be at risk of receiving a much lower quality education that is overly-reliant on poorly built computerized teaching systems or online learning courseware that does not provide the kind of encouragement and motivation that is required to help students through the 
many challenges encountered when learning. Following this path could well lead to a self-perpetuating system across generations where a small elite group benefits from a compounding level of social capital, while most students are left out, leading to a widening of social, political, cultural, and financial gulfs.

\section{Protecting and Supporting Diverse Points of View}

Higher education institutions hold sacred the ideal that their communities protect everyone's ability to make their arguments; that the pursuit of knowledge requires a free exchange of knowledge and perspective, and that the use of evidence, scientific inquiry and vigorous debate are essential pillars of a democratic society and social and technological progress. There are a number of factors that are threatening higher education's ability to continue to serve that role for all perspectives:

- What are facts? The very assumption that there are facts and that truth can be pursued and realized through scientific inquiry is being questioned. Sometimes this skepticism about the concept of "truth" stems from politics or ideology, sometimes it is rooted in beliefs about different forms of knowledge and "ways of knowing."

- Controversial speakers are unwelcome. Demonstrations and the threat of violence associated with providing a platform for controversial speakers threaten the ability of higher education institutions to serve as the host for important conversations and to serve as defenders of free speech.

- Social media demands a response at a furious rate. The enormous power of social media to stir controversy and to move opinion and emotion operates at a pace that intellectual arguments cannot match. This results in leaders having to react rather than reason when faced with political challenges.

- The academy leans left. Through a process of self-selection over a matter of decades, a super- majority of the professoriate and administration in the academy have political views that are left-of-center. This is helping to create a perception that higher education is not a welcoming environment for all perspectives. As Lawrence Bacow said at his installation address at Harvard University, "more people than we would like to admit believe that universities are not nearly as open to ideas from across the political spectrum as we should be."2

\footnotetext{
${ }^{2}$ Lawrence S. Bacow, "Installation Address," Harvard University, October 5, 2018, https://www.harvard.edu/president/speech/2018/installation-address-by-lawrence-s-bacow.
} 
- There is less room for nuance. The increasing stridency of debate and dialogue in the political sphere, driven aggressively by ideology and partisanship, undermines the making of arguments based on careful and nuanced intellectual reasoning.

Higher education needs to combat the perception as well as the reality that it is no longer a place where ideas can be truly and freely shared without fear of repercussions.

\section{Defending Important Values}

In addition to nurturing multiple points of view, colleges and universities are long-lived institutions that have stood for timeless values such as the disinterested pursuit of learning, the freedom to conduct research on important questions of every kind, and the importance of enlightened reason. Yet, these institutions are threatened from multiple directions, and many, if not all, of the problems framed here threaten these institutions' ability to protect these values. For example, the increase in the need to support computer science and data science majors at the same time that the number of humanities majors is falling dramatically is a direct response to "the market" for students and by the needs of students. There is nothing inherently wrong with that, but it steers these institutions toward the practical and away from the philosophical. It also raises the question of whether higher education institutions are motivated by their values, or if they have become more akin to corporations driven by meeting the needs of consumers and responding to challenges to their financial sustainability rather than by their values and mission. This shift is occurring at a time when a rich understanding of the humanities is arguably more important than ever. Our increasing reliance on machines to support and even replace some of our intellectual work is going to raise ethical and philosophical questions that only an understanding of the humanities will help us to address.

\section{Sources and Sustainability of Financial Support}

Over the last 30 years, and at an accelerating rate since the Great Recession, higher education has been receiving a decreasing share of the public purse. J ames Duderstadt, former president of the University of Michigan, in his 2009 address Dies Ademicus, said:

Actually, this decline in public support was nothing new for my university, located in the Rust Belt close to Detroit and the collapsing American automobile industry. Over the past 30 years we had seen our public support decline from $70 \%$ of our operating budget to less than $6 \%$ (more specifically, state support of $\$ 322$ million/year compares to the total University of Michigan budget of \$5.5 billion/year). As university president I used to explain that during this period we had evolved from a state-supported to a state-assisted to a state-related to a state- 
located university. In fact, with Michigan campuses now located in Europe and Asia, we remain only a state-molested institution. ${ }^{3}$

More generally, in academic year 2005-2006, state governments covered 36 percent of public 4-year doctoral institutions' budgets. By 2010-2011, that was down to 29 percent, and it has continued to fall, to 27 percent in 2015-2016. ${ }^{4}$ There are a number of reasons for this diminishing public financial support:

- Other costs, such as for health care and pensions, are crowding out resources that mightbe available for education.

- There is a general reduction in investment in public programs and institutions as governments have moved to the right of the political spectrum.

- Support for higher education is increasingly becoming a partisan issue. In J une 2017, a Pew Research survey showed that 58 percent of Republicans say that colleges and universities have a negative effect on the way things are going in the country. ${ }^{5}$ Similarly, just published Gallup poll found that higher education suffered the greatest drop in confidence among a variety of public institutions between 2015 and 2018, falling from 56 percent to 48 percent. The drop in confidence was largest among Republicans, falling 17 percent from 56 percent to 39 percent in that three-year period. ${ }^{6}$

- Many colleges and universities have been forced to raise tuition in order to close the gaps caused by reduced public funding, creating something of a vicious cycle as increasing tuition leads to increased dissatisfaction or frustration with the institutions. It has also contributed to rising levels of student debt, which has become its own political challenge for higher education.

\footnotetext{
3 James J. Duderstadt, "Current Global Trends in Higher Education and Research: Their Impact on Europe," Dies Academicus 2009 Address, March 12, 2009, https://core.ac.uk/download/pdf/3146623.pdf.

4 "Institutional Revenues per Student at Public Institutions over Time," College Board, https://trends.collegeboard.org/college-pricing/figures-tables/institutional-revenues-student-public-institutions- over-time.

${ }^{5}$ Hannah Fingerhut, "Republicans Skeptical of Colleges' Impact on U.S., but Most See Benefits for Workforce Preparation," Pew Research Center, July 20, 2017, https://www.pewresearch.org/fact-tank/2017/07/20/republicans-skeptical-of-colleges-impact-on-u-sbut-most-see-benefits-for-workforce-preparation/.

6 Jeffrey M. Jones, "Confidence in Higher Education Down Since 2015," Gallup Blog, October 9, 2018, https://news.gallup.com/opinion/gallup/242441/confidence-higher-education-down-2015.aspx.
} 
- Many other colleges and universities have reduced core educational expenditures and cut other services in response to the decline in public funding, which has had an impact on the likelihood that students will complete their degree and certificate programs, in addition to further alienating multiple constituencies.

\section{Conclusion}

The problems facing higher education are coming at the sector fast and furious, and from all angles. Multiple books would be needed (and have been published) that attempt to address some or all of these challenges. This brief paper aims neither to be comprehensive nor to suggest solutions to these vexing challenges; rather, its only goal is to offer a simple framework that might help leaders simplify, focus, and assess the challenges in their own contexts. Ultimately, we need for our rich diverse ecosystem of colleges and universities, public policy makers, and the organizations that support and partner in their work, to be positioned to defend, protect and sustain higher education's extremely important role as a trusted source of knowledge, education, and freedom of inquiry. 